\title{
Erratum to: Cellular Prion Protein Promotes Neuronal Differentiation of Adipose-Derived Stem Cells by Upregulating miRNA-124
}

Fushan Shi ${ }^{1} \cdot$ Yang Yang $^{2} \cdot$ Tiancheng Wang $^{3} \cdot$ Mohammed Kouadir $^{4} \cdot$ Deming Zhao $^{5}$. $^{2}$ Songhua $\mathrm{Hu}^{3}$

Published online: 25 April 2016

(C) Springer Science+Business Media New York 2016

Erratum to: J Mol Neurosci

DOI 10.1007/s12031-016-0733-8

The original version of this article unfortunately contained a mistake in Fig. 1. The correct version is presented below.

The online version of the original article can be found at http://dx.doi.org/ 10.1007/s12031-016-0733-8.

Songhua $\mathrm{Hu}$

songhua@zju.edu.cn

1 Zhejiang Provincial Key Laboratory of Preventive Veterinary Medicine, College of Animal Sciences, Zhejiang University, Hangzhou 310058, China

2 College of Animal Sciences and Technology, Zhejiang A\&F University, Lin'an 311300, China

3 Department of Veterinary Medicine, College of Animal Sciences, Zhejiang University, Hangzhou 310058, China

4 Trustchem Co., Ltd., Nanjing 210029, China

5 College of Veterinary Medicine, China Agricultural University, Beijing 100193, China 


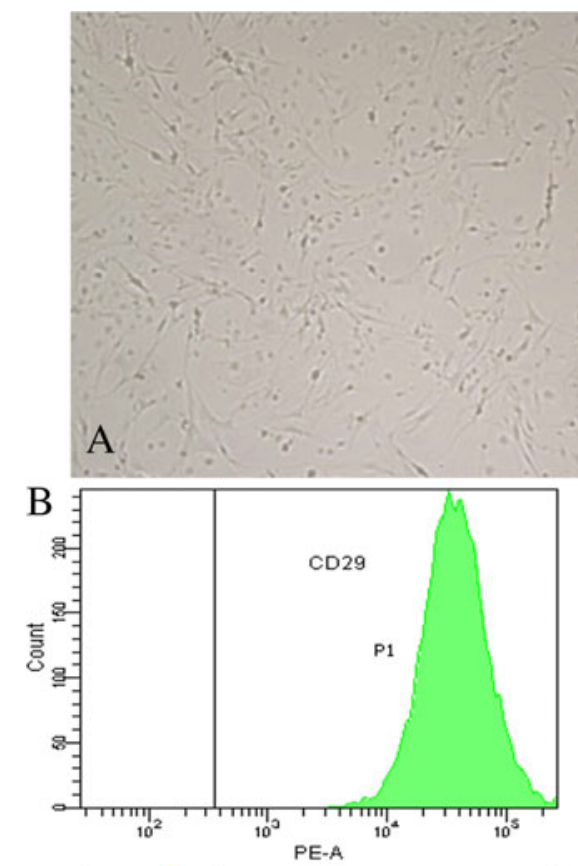

ADSC

Neural differentiation

C

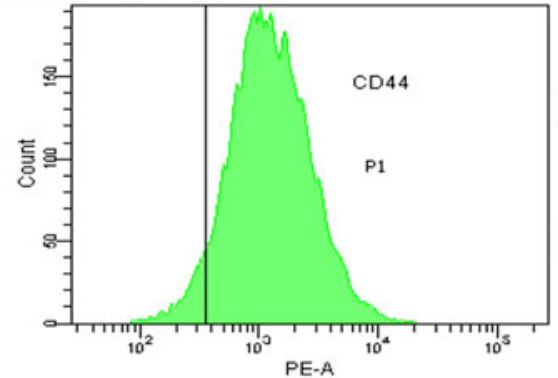

D
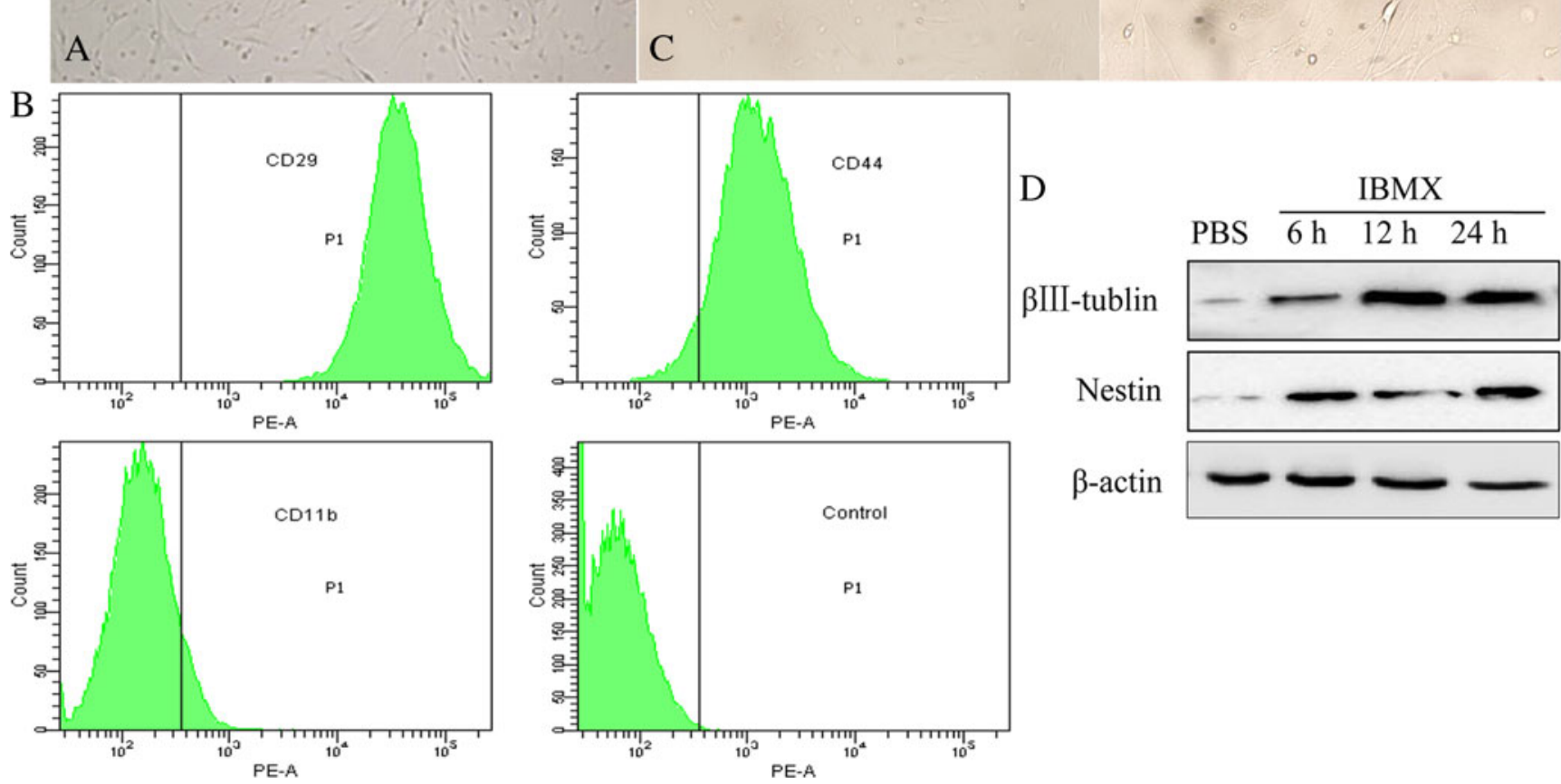